\title{
The Principles of Language Learning and Teaching in Communication Skill Developments
}

\author{
${ }^{1}$ Dedi Aprianto, ${ }^{2}$ Novian Zaini
}

\author{
${ }^{12}$ STMIK Bumigora Mataram, Indonesia \\ Correspondence: Dedi Aprianto, STMIK Bumigora Mataram, Indonesia. e-mail: dedi@stmikbumigora.ac.id
}

Received: Februari 27, 2019

doi: 10.29408/veles.v3i1.1281.g746

\author{
Accepted: March 04, $2019 \quad$ Online Published: April 15, 2019 \\ URL: http://dx.doi.org/10.29408/veles.v3i1.1281.g746
}

\begin{abstract}
A language has two different and integrated skills, the receptive skills and the productive skills. Surprisingly, a speaking is a part of the productive one, as one of the main skills of all. It is also categorized as the micro ability salient for an effective communication and a global means of communication within both social interactions as well as digital communication. The development of the micro ability must have been considered by paying attention toward the principles of language learning and teaching; needs-based curriculum, learning methods, and the theoretical basis construction. The strong consideration of the basic principles of language and teaching gives the nuance and the insights towards both language teachers, curriculum makers, as well. The use of Communicative Language Teaching (CLT) reflected from what is rooted in Hymes' theory emphasizes on Communicative Competence as a social interaction and functional rules of human language (Constructivism Theory). Whereas the Chomsky's notion of Communicative Competence based on the psycholinguistic perspective depicting a language has two concepts, namely competence and performance (Nativist Theory). Finally, a language is seen as a phenomena observable and even process of automaticity. It focuses on the relationship of stimuli-responses by strengthening that relationship through more exercises/ practices.
\end{abstract}

Keywords: The principles of language learning and teaching, speaking skills, and communicative competence.

\section{Introduction}

Every language has skills which are mostly termed as the integrated language skills; these would have closely-interlaced one other. Contextually, the relationships of receptive skills and productive skills are strongly getting in touch in a continuum. To learn receptive skill must produce the productivity of the productive ones; the former, listening and reading, the mental and physical process, absorb the information released by. Whereas, the latter speaking and writing skills produce what is encoded from. in this case, speaking, a productive skill, is categorized as one of the micro ability which is salient for effective communication. 
Nowadays English could have been considered as universal means of communications, both real social interaction and digital communication usages, such as English-based internet world. Eventually, speaking skills should be developed with the other skills, so these might have enhanced the communicative skills (Boonkit, 2010). To make the communicative skills posed the significant role, as Bailey and Goh (in Boonkit, 2010) detailed the ways of fostering the speaking skill in terms of ELT Cycles that fostering the communicative ability enhanced by means of syllabus design, considering the principles of teaching and learning, and material developments should be taken for granted.

Learning a foreign language is like learning mother language, an inevitable process, foreign language learning could be taken for consideration as a special accomplishment. In fact, learning a foreign language might have found the intricacies, it is because of the reason; the foreign language learners might have experienced the first language, meaning that foreign learners of English attempt to learn a foreign language through the ways of first language they acquired. Moreover, Mockey (1996, in Al Ahdal, et. al, 2014), writes that learning a second language can take variety of patterns; the learning of second language is greatly affected by linguistic and sociological factors. Besides, the psychological factors could affect the process and progress of second language learners such as, age, motive, native skills, intelligence, personality, auditory memory span, intention, readiness to learn, emotion, and drive. Thus, of all those factors might have been affecting the learners' foreign language learning. According to Tagachi (2002, in Brooks and Wilson) noted that the teachers seem to focus on the vocabulary and grammar drills, as English communication as the target of learning gets left by the wayside and also less English training specialized for enhancing the communicative proficiency. Thus, they are the score of reasons why teachers feel hard to teach their students by using communicative English in classroom. So, the students' inexperience for using oral English can be categorized as poor English usage. In this case the practice of having the language, participants take the initiative by thinking beyond the mandated textbooksi instead by using language communicatively and purposively. As Brooks and Wilson suggested that breaking down the problem by applying the oral presentation in classroom might create several advantages for classroom effectiveness such as, situation can be students-centered learning, meaningful activities; most of the students enjoy taking part in creating their own contents of course (Brooks and Wilson, 2014).

\section{The Principles of Language Learning}

The need of the communication skill in the real world lets curriculum designer do the revision toward English learning curriculum, so the evaluation of the communicative language teaching is deemed as the theoretical principles as well as its practice in an EFL teaching in Arabic world (Darwish, 2016). It supposes that the use of CLT as a teaching approach suggesting both as the new language teaching approach and as the post-method area which can achieve the goals of English language learning and meets the needs of language learners as well as language teachers. In addition, Darwish noted that the term 
Communicative Language Model is the big umbrella for all teaching methods having goals to achieve the students' language's communicative skill. This is proven by some teaching practices utilizing the other language teaching methods, as in Task-Based Approach, Humanistic Approach, and even Total Physical response method. These are practically done through a communicative ways. In sum, a communicative language approach embraces all kinds of teaching practices (Darwish, 2016). Principally there is no a special language method that can both achieve the goals of English as a foreign language learning and meet the needs of the language learners as well as the language teachers.

A communicative language methods has taken account the characteristic features on the classroom participation. It lets the classroom participation depict on learner's communication activities. Fortunately, the essence of CLT as a way to do an EFL learning method triggers the students to ultimately learn a target language as well as they must depend on the language learning effort. CLT, a language learning approach, reflects some certain models, research paradigms, or language learning theories (Celce-Mercia in Darwish, 2016). It strongly underlies on the theory having foundation of the language use is a communication activities. In other words, the theory puts its emphasis on the social interaction which is not as the ultimate goals of language learning only. In relevance with Hymes' concept on the social rules of the language use is a concept of communicative competence. It is not just as a term, it is a basic concept to understand social interaction. The use of such a foresaid concept has very important implications for a language learning rather than linguistic interaction in the target language (Paulston, 1972 in Scarcella, et al. 1990). It would have leveled against the Chomsky's concern on linguistic competence. Eventually, Dell Hymes suggested a social rule deemed as a tool to understand and produce both referential meaning and social meaning. Many sociolinguists have attempted to investigate and understand on the rule of speaking which is focusing on the utterances and they invested them as a social meaning. The use of a social meaning refers to what Hymes said I would go beyond the social meaning of language. This suggests that the social meaning is so important in a language learning and teaching. From this term, he additionally mentioned a model of language learning designed by a face toward communicative conduct and social life (Hymes, 1972, in Paulston, 1967, in Scarcella, et al. 1990), which is intended to execute in terms of English language learning practices. Moreover, this model of language learning might have set up the stated framework to identify and even discuss the language learning strategies and techniques in learning process taking into account the social meaning of a human language (Paulston, 1972, in Scarcella, et al, 1990).

The use of the model of language designed by face to face communication is a part of the designed language learning outcome. In CLT, the student-centered learning must have been considered as the most important in executing functional language learning. A studentcentered learning might be utilized as model of language learning, in case it would have given a priority toward language learners to the language learners to use the language as the social practice. The use of language speaking skill is categorized as the heavy skill that triggers the language users to perform the complex operations in accurate as well as quick sentences. This 
is what suggested in the article entitling Principles of Language Learning and the Role of the Teacher, the TESOL International Association (2017), that there are two ways which language learners must do, as in; a lot of practices and the repeated practice. Learning to speak well, a student needs to spend lots of times for practicing a target language. Learning a language needs a lot of times to practice can improve the language skills; listening, speaking, writing as well as reading. In addition the concept of automaticity is a language learning concept. It is today still utilized in terms of practicing language learning. Thus the concept of automaticity is closed-related to language learning principle (Omaggio, et al. 2001, in TESOL International Association 2017). This way requires the language learners to the different skills in the same time. In a speaking skill, a student can choose words, apply the grammar rules, and practice the pronunciation as well as intonation. These must be practiced often enough. They can automatically be performed and in a repeated way.

Regarding to the principles of language learning and teaching, models of language learning appear in recent years. The study conducted by Al Harbi (2015) reveals that the absence of authentic language learning situations performed outside the formal classroom presents the significant challenge to improving students' English communication skills. The investigated obstacles found in doing communicative activities were caused by the students' limited use of English speaking inside the formal classroom. This situation is close-related toward what Hymes' theory on a social meaning, to practically use the target language, in the contexts of English as a Foreign Language use. Such a significant study gives the nuance as well as the insights toward language teachers, language curriculum designers, as well that the problems found in building the active classroom participation in the contexts of English as a Foreign Language countries. There are some implications which those must recommend as well as do, as in; (1) making the specific curriculum toward emphasizing the communication skill through reforming the Ministry of Education and Culture to use the Communicative Language Learning (CLT) curriculum, (2) strengthening the use of a functional language methods, like CLT, Interactive Language Learning, well. Furthermore in the context of CLT as a language learning approach in school curriculum raised two general problems; the choice of language skills needed; what pragmatic aspects should be taught or what language skills does students learn and what grammar rules will be taught. The second problem is relating to a language method which is utilized to do communicative language learning, in favor of developing students' communicative competence. Thus the last problem encompasses two important issues, namely language syllabus, the strategies of language learning, as well best suited for needed materials (Huda, 1999). In the theoretical perspective, Communicative Language Teaching was rooted from what Dell Hymes (1972) said on a Communicative Competence, as the reaction which is against the concept of a Communicative Competence proposed by Chomsky, the psycholinguistic nature (1965). The two different conceptions on a term communicative competence proposed a writer would like to address what Chomsky's classification of such a foresaid concept, namely competence and performance. A concept of competence, the Generative Transformational Grammar has two firmly-stated types of language structures namely surface structure and deep structure. The previous is as the 
manifestation of deep structure, the later has the different form from the deep structure, but the meaning consisted of is essentially the same (Huda, 1999).

Just the opposite, the communicative competence developed by Hymes accounting for the communicative competence as the aspects of English as a Foreign Language (EFL) learners' competence to interpersonally convey, to get as well as to negotiate the meaning of a language within a specific contexts (Brown, 2000). In sum, the different concepts with Hymes (1972) along with Chomsky (1965) casts light upon that communicative competence has distinguished between linguistic competences with communicative competence itself. They are referred to knowledge on linguistic forms and knowledge on the functional and interactive language (Paulston, 1974 in Brown, 2000). They were sufficiently termed as Cognitive/Academic Language Proficiency (CALP), Basic Interpersonal Communicative Skills (BICS), as well (Cummins, 1979 in Brown, 2000). CALP is the manifestation of a formal language learning focusing on the surface features of a language outside the interpersonal contexts while BICS is the communicative capacity possessed by the language learner, in order to functionally take social and interpersonal exchange. These later on are termed as a form of context-reduced communication and a form of context-embedded communication (Cummins, 1981 in Brown, 2000).

The principles of EFL/ESL learning must determine of what is foresaid above on determining the language syllabus as well as the language strategies. In determining the two big issues on EFL/ESL language pedagogy, there are two aspects that underpinned toward the syllabus and language learning strategies consideration, namely the psycholinguistic aspect and the socio-cultural aspects (Huda, 1999). According to Michael Canale and Merrill Swain (1983 in Brown, 2000) suggested that in their seminal work on communicative competence which has four domains of knowledge and skills which must be pre-determined. The four different subcategories developed by Canale might have made construct of communicative competence (Brown, 2000). Language learning materials have been categorized into the reflection of the use of the linguistic system itself, and the others are the functional aspects of contexts-embedded the social and interpersonal communication.

\subsection{EFL/ESL Learning Syllabus which can be used to design sorts of language learning curriculums, as in:}

\section{Grammatical Competence}

In Huda's citation on what Canal accounted for on the grammatical competence that it is linguistic competence by mastering the formal codes of the human's language grammar within both verbal and non-verbal competence. It is additionally addressed by Brown communicative competence consisting of the aspect of lexical item knowledge of rules in morphology, syntax, semantics, and phonology (Canale \& Swain, 1980 in Brown, 2000). These are called as the formal linguistic competence. 


\section{Discourse Competence}

The second category concerns with the complement of the grammatical forms or the combination of the grammatical forms and the language meaning to produce either verbal or non-verbal language. According to Brown (2000), this means that the language learner's ability to both connect the sentences in the stretches of discourse and to wholly construct a meaningful series of the utterance produced. The understanding of the utterance could have been reached through the cohesion of linguistic form, meaning coherence, as well. The cohesion is the relationship of the utterance with the grammatical structure enabling the language learner to interpret the discourse meaning while coherence is the relationship among several meanings in the utterance or texts (Huda, 1999). Thus in Brown (2000), the discourse competence concerns with the intersentential relationship in the utterances or texts (books, articles, and the like).

\section{Sociolinguistic Competence}

This category deals with the knowledge of the socio-cultural rules of language. This social competence, in the school curricula, requires the understanding of linguistic context in which a language is used. The language learner's sociolinguistic competence describes about to what extent the language is expressed and correctly understood in different sociolinguistic contexts (Huda, 1999). The contextual meanings can be identified through the roles of a speaker- a listener (the participants of a conversation), the objective of the interaction, the rules or norms of the social interaction. In sum, only the full context possessed by the social interaction can make the judgments or the appropriateness of the language.

\section{Strategic Competence}

This is the last category of communicative competence as a domain of strategic language competence to determine the preferred language curricula in pedagogy. A strategic competence is the ability of verbal and non-verbal communication strategies to cope with the breakdowns in communication due to insufficient competence or the limitation of circumstance. In Brown (Savignon, 1983), it is the strategic competence that the language learner can use to repair the imperfectness of rule knowledge in the language application. In addition, this is used to strengthen the effectiveness of the communication through several ways like paraphrase, circumlocution, and repetition, etc. (Brown, 2000).

\subsection{Strategies of a Foreign Language learning / a Second Language Learning}

The second issue in the principles of Second Language Learning (SLL) or Second Language Acquisition (SLA) concerns with the strategies which can be used by the language learner to develop the communicative competence. In this regard the language learning strategies could have been considered by adapting to the objectives of language learning by adjusting toward the three theories, as the basis, in purpose of developing the language learner's communicative competence (Huda, 1999). 


\section{The Behaviorist Approach}

The traditional behaviorists thought that learning must be intended to develop the second language acquisition. Thus this can be considered as the strategic language learning method. Effective language learning is as the result of process of imitation, regular practice, feed-back on success and the habit formation. The cognitive approach mostly dominated the educational psychology. However as the overriding trend in educational psychology, American and European curriculum considered as the associationist in nature. School curriculum is viewed as a collection of the association which student may learn to. Eventually the association refers to the relationship stimulus ad responses whereas the exercises were designed to strengthen these associations. Thus the focus of this approach is on the association of stimuli and responses (Tomic, 1993). In sum, the behaviorist approach is assumed to focus on the relationship of stimulus and response theory which will be developed. According to Huda (1999) human language understood as a set of habitual process, regularity and retention, having two characteristics, namely observable phenomena, the internal process are ignored while the second one, automaticity obtained through more drills as well as practice. Moreover, the drills and practice are seen as stimulus, whereas the speaking performance of the students' is seen as response that is strengthened through reinforcement. Practice is defined as the transfer of a language skill to another which can happens to the sets of one language's habits to that of another language. It is urgent that no every language's habit transfer can benefit the language learners. When the transfer of language's habits and features will be the same as the other, the facilitation will be served. On the other hand, As the L1 and L2 distinctively happen; these will be difficult and interfered as the emergence of language errors (Huda, 1999).

It is familiarly known that such principle as the basis for developing one of language learning techniques, estimating the language errors, is called as Contrastive Error Analysis (Lado, 1957 in Huda, 1999). She moreover addresses the Behaviorist language learning theory was thought as the basis for developing the Audio-Lingual Method reaching its popularity in 1950 s to 1960 s.

\section{The Nativist Approach}

This argues that language competence is developed within language learner's inner factors in which human being is born with the innate capacity to mastery the language or what is called as Language Acquisition Device (LAD). This device will operate if the language learner is exposed to the targeted language. It is known that this device will make a language learner creative and productive in making linguistic utterances which he or she never hears before. The nativist language learning approach theoretically is derived from the fundamental assertion that language acquisition is innately determined. This is what Brown said (2000), a human born with a generic capacity affecting a language learner to a systemic perception of language that results in the construction of an internalized system of language. It is also called as generative understanding of language acquisition; the aspects of the theory of syntax in 1965. In sum human comes with LAD, as the innate pre-programmed ability for human to 
genetically share a common human's trait (Hopkins, 2017). The theory of language learning on the relationship of stimuli to responses is rebutted by the nativist language learning theory that Chomsky said; human has an innate, inherited, Neuro-structural capacity which are not explicitly taught nor implicitly experienced of what is called as Universal Grammar (Hopkins, 2017).

Mechanically, the hypothesis of innateness has been supported by some applied linguists, such as Lenneberg (1967 in Brown, 2000) suggested that human language is a 'speciesspecific' behavior. Then he additionally argued the specific species which certain models of perception, categorizing abilities, and the mechanic features of language are biologically determined. Similarly Chomsky claimed the existence of children's innate properties of language to explain their native language mastery in such short time even though the highly abstract nature of the rules of language. The innate properties are embodied in what is called as a little box, Language Acquisition Device (LAD). According to McNeill (1966 in Brown, 2000), it has innate linguistic properties in human being namely the ability to distinguish speech sounds from the other sounds, the ability to organize the linguistic data into various classes that can later be refined, knowledge of certain linguistic systems is possible and the other is not, and the ability for engaging in constant evolution of the developing linguistic system in order to construct the simplest possible system out of the available linguistic input.

The development of Chomsky's LAD theory then accompanied by some increasing theories on language acquisition as Krashen's (1981) and Bialystoke's (1978) theory of monitor. Fortunately theory has produced a considerable contribution toward the second language acquisition studies is the difference between the implicit and explicit linguistic knowledge. The difference of that of linguistic knowledge can be termed as language acquisition for implicit linguistic knowledge and language learning for explicit linguistic knowledge. The implication of these terms is the implicit linguistic knowledge which is naturally obtained. On the other hand, the knowledge of explicit linguistic system is formally obtained.

In sum the implicit linguistic knowledge as the sources of the communicative competence and the basis for taking consideration for the communicative language learning approach. In the generative perspective, Chomsky noted that all normal infants can acquire the comparable grammar of the complexity remarkably (Chomsky, 1959 in Hopkins, 2017). He additionally argued a language is a stimulus independent where every child has the capability to rapidly develop the language skills semantically as well as pragmatically. Then the availability to recall the language skills is required within the meaningful syntactic sequences to produce the infinite meanings which are not seen and experienced.

\section{The Interactionist Approach}

In language acquisition realm, the three major schools of thought in language acquisition have contributed to specific output in the theoretical underpinning construction toward language acquisition process. Behaviorism language learning approach particularly tends its focus on main role of the environment and introducing the concepts of imitation and habitformation/practice. Conversely, the Nativist language learning approach focuses on the role of 
mind and cognitive process in language acquisition and language learning (Sarem \& Shirzadi, 2014). Constructivism school of thought is properly thought as the new emerging trend in language acquisition and language learning. It is considered as one of the main foundations affecting the trends, approaches, and the language theories. This theory has strongly had a great impact toward the interactionist approach in SLA (Sarem \& Shirzadi, 2014). It is called as the Constructivism paradigm, too. The availability of the Constructivism approach, as the prevailing paradigm is the last part of the twentieth century, could have been seen as a shift from Behaviorism, Cognitivism/Nativism to Constructivism. The shift has not been so much away from the Generative side/Nativism to the Constructivism, but the process of its shift is better described as tending deeply to the essence of a language (Brown, 2000). The Interactionism approach is focusing on the social interactions in language acquisition and language learning. Moreover, in this approach, the language learners should be exposed to have comprehensible, negotiated, or modified inputs in the language learner's attempts to acquire a language (Sarem \& Shirzadi, 2014).

In light of the shift of the previous approach to the new one which has given insignificant change. This can be seen as the Constructivism arguing that all human beings construct them own version of reality, and then the multiple interesting ways of knowing and describing are all considered being equally accepted (Brown, 2000). The Constructivism approach lets the language learners focus on the collaborative engagements in the social practices in form of a collaborative group or in a global community (Spivey, 1997 in Brown, 2000 in Shirzadi, 2014). In sum according to Brown (2000), the Constructivism concentrates its emphasis on the primacy of each individual's construction of reality. Principally the Constructivism approach tends to concentrate on the social contexts, but there are two different perspectives in the extent to which each emphasizes the social contexts. Piaget (in Shirzadi, 2014) puts his focus on the importance of individual cognitive development as a relatively solitary act, the biological timetables, and stages of the development were basic. The social interaction has been claimed to trigger the development at the right moment in time. On the other hand, Vygotsky (1978 in Brown, 2000 in Sarem \& Shirzadi, 2014) argued that social interaction was fundamental in cognitive development and it rejected the predetermined stages. In sum the Piaget's cognitive perspective claimed the social interaction is given a secondary role, while the Vygotsky's perspective stated the social interaction was something primary for development (Hickmann, 1986 in Sarem \& Shirzadi, 2014). Thus the two linguists have different perspectives in a case of the relationship of social interaction with language acquisition. Piaget additionally suggested a language has a proportional and contextindependent property. Moreover he said that it is a tool for abstract reasoning, whereas the context function and the social functions of the human language have been given a secondary role in a language acquisition. On the contrary, Vygotsky's notion claimed that social interaction and the dependence of context are primary in a case of language acquisition. In addition, the meaning of language is socially constructed and emerges out the learner's interaction with the social environment (Vygotsky, 1978 in Sarem \& Shirzadi, 2014). In other notion of the Interactionist theory, this emphasizes the role of individual. which suggested the 
importance of meaning-making. Another is active role of learner as the basic element which makes the theory appealing towards educators (Jones \& Araje, 2002). It is in line with what Muho and Kurani's research suggests the role of interaction in SLA employed by the English teachers. Muho and Kurani revealed that the input theory, and interactional modification theory which facilitated the second language acquisition. As a result is the importance of social interaction in case of SLA. There are more opportunities given toward language learners in classroom for an oral discussion, encouraging the students to initiate the topics and having them do the responsibility to take part in a social communication. From this initiative, the language environment would be creative, productive, initiative and enjoyable (Muho \& Kurani, 2011).

Finally, a writer intends to go to the conclusion on the Interactionist language learning approach. He follows what Huda (1999) Suggested that it sees a language acquisition as the result of the combined works of the internal factors and the input. Then the development of communicative competence is the combined result of language learners' efforts and the environments or their speaking partners (Ellis, 1986 in Huda, 1999). In light of language acquisition process, learners doing an acquisition of a language enable to occur when the input can comprehensibly be accepted by the learners. The meaning of a language which can merely be made comprehensible must be integrated and met by contexts, world knowledge, and the language learners' linguistic competence (Krashen, 1985 in Huda, 1999). Finally, the importance of input can worthily considered that it is very meaningful as well as comprehensible to the language learners. The understanding / meaningful input can be proven through the use of simplified structures, high frequency words, and the avoidance of specific expressions. The second is interaction where the interaction modification is in form of the repetition of the utterances, asking for classification (speaking participants), asking for meaning confirmation, and rephrasing (Huda, 1999).

The availability of another theory might have given an emphasis on the priority of communication skill through oral classroom participation that is the theory of language acquisition's relation with classroom interaction. The relationship between classroom participation with language acquisition can be proven. This suggests that language learning; the oral correctness was influenced by the students' participation (Tson, 2005). Curriculum development is not only viewed as the total changes of whole aspects of the curriculum itself, but also viewed as the partial aspects of language. In the foresaid passage the role of students' need must be stuttered as well as possible, so the need-analysis is inevitably stipulated. In line with this statement, in curriculum innovation the integration between language learners' socio-cultural background, the previous language experiences of the learners', and the influence of teachers' theoretical view of language learning strategies must meet. The classroom interaction can thoroughly be discerned that the use of effective language teaching technique and the other students' classroom participation. It can possibly be reached if the language teachers must not only teach the language but also understand how to be a language learner. Understanding about how to be a language learner in classroom by convincing the students about the values of a communicative language activities which can be displayed 
through a discussion, role-playing, and problem solving. Eventually a curriculum development will worthily be targeted if the sensitivity and perception of the students along with the willingness to effectively consult and to negotiate.

\section{Communicative Skill Improvements}

The intensive term of language improvement is the first three years when the brain is amending as far as progressive process. The language primacy whice achived preceedingly is the communicative language that intended within a prior aim in learning foreign language. It is salient to learn a foreign language by utilizing communicative language method. Therefore spoken language is far more prominent than written one. It is alleged that language improvement towards communication matter is basically centralized as the initial tenet to faster other competences for instance Listening, Writing and Reading. The four skills must be integrated one other, in addition one whose great speech would be then absolutely illustrative toward prospective highlight such as reading and thinking skill instead of fellow who lacks off sufficient communicative competence, so that it could have distracted one's pep to interact properly. It is the interrelatedness of the linguistic arts. It is said to find the group of children who were high in general language ability were also high in reading ability, while those who were low in general language ability were also low in reading ability and that children who were proficient in oral language were also profiently in written language. Language is more than a tool for communication; it is an avenue for creative expression, speech and language are tools which humans use to communicate or share thoughts, ideas, and emotion. As the result a fellow who has high ability in spoken matter will be probably proficient in reading, but fellow whose insufficient competence to communicate his own idea, thought and argument could have been unfortunately despised to grasp written language. Communicative method would rather rely on student's creativity through practical highlights. Communicative language method (CLT) is a learning approach of second language which is in need of interactional pedagogical cores as the vehicle and post aim of foreign language learning process. It is named as a communicative approach within teaching a foreign language or historical communicative one. Communicative language method (CLT) considered as both response of Audio Lingual Method and syllabus extenfication. It is distinctive that to count for communicative phenomenological than others. The coursework formulation would rather be encountering about communicative work such as discussion, debate, presentation and conversation. What is called as grammatical method's circumstanced highlghts are not nearly equel as those of Communicative Language Method in case it is rarely in need of grammar matter. The grammatical course is settled as an illustrative matter against the communicative matter.

Using the communicative language method is one of the enormous ones which many responses regard as an unsophisticated way to understand and to learn a foreign language because it can help students to conform with it. Many strengths that student absorbed a communicative method not only the interactive matter which could be applied but mastery on the four skills of English as well. Speaking is considered as an integral part of the productive 
skill which must be integrated in the developments of effective communication ability. Of all the four integrated English skills, speaking is ranked as the most important skill required to make the communication ability up. One of the benefits of the effective communication which done through interactive speaking would have resulted a number of benefits for speakers and business organization, such as job interviews, job training activities, and ceremonial speaking activities. Additionally, speaking ability has a good experience, motivation, academic credentials as the stated fulfillments for work vacancy. Unfortunately, it is known that English for the spoken ability would be the most difficult skill to increase in case it is supposed that the situation of Indonesian context might provide less support for learners. It is because English learnt in school is not used as English as second language. So, this condition does need the developments of English materials as well as teachers should have considered that the principles of ELT must be made up, in forms of communicative approach and functional conception implementation.

One of the ways to promote the communication skills is to take the inclusion of the communicative approach in the curriculum. As suggested by Huda (1999), there are two problems causing the use of communicative approach in ELT that it is related to the choice of skills needed to be taught, in terms of the prospective of learners to pursue the goals of learning. And the second problem is suited best to the syllabus and learning strategies which must be associated with the materials. In keeping with fostering the speaking ability, it is revealed towards the study was conducted by Boonkit (2010), by raising up the effectiveness of communication ability could be employed by confidence building-up, it is taken for granted as the most strengthened factor in terms of showing the speaking performance up. In addition to such study, he also used the task-based speaking for specially-made communication (situated speaking). In this case, speaking situation which is set up or designed into the courses also helped participants to prepare for speaking. Furthermore, it could have supported learning atmosphere and made the more effective learning strategy to both minimize the learning anxiety and maximize learning confidence. The initiatives taken for consideration by both the curriculum makers and English teachers can help the students have so far been successful in goal-reached learning. By way of having the fluency, accuracy, good pronunciation in the oral productive skill might have been standing a better chance of securing a good job in employment world (Farooqui, 2007).

Students' academic purposes must have been in line with their prospective later on by designing the material which must be taken for granted. It is caused by consensus of the global competitiveness as the keystone for the future economic success. This notion is revealed by a study conducted by Tsou in National Cheng Kyung University (2009) attempted to re-conceptualize a project in language learning towards raising up the average second language proficiency of the college students and address the specific academic and occupational needs. Thus, determining student's needs in learning objectivity depicts a systematic framework to conceptualize English learning materials. In this case, materials development have might been emphasized on the functional usage of the language, hence it is prioritized medium of communication. As stated by Ellis and Johnson in Hossain's (2013) view with the needs of rapid communication being what they are today, proficiency in a 
common language is a necessity. So, in economic global world and technology progress require the employees with better proficiency in speaking English. Accordingly, the secondary as well as the tertiary students have to prepare themselves to learn English wellcommunicatively to fit for the job market. So, English teachers have to improve students' communicative skills by emphasizing the attainment of students' needs. In addition to the materials development, the framework of material designing must meet the learners' needs.

\subsection{Communicative Language Approach}

English speaking is the most important skill which must be integrated in terms of fostering learners' language proficiency. Speaking, as the productive skill, is taken for granted as the prominent direct means of communicating the ideas through a language. Furthermore, having an effective speaking indicates very good proficiency. To enable to make language learners conscious in terms of communicative proficiency in which a teacher should make the materials as well as the language learning strategy as well as possible. Theoretically, the communicative language teaching is rooted from Dell Hymes in 1972. Moreover, such theory is supported by the other linguists, Halliday (1973) and Canale (1983). The theory of the communicative competence which focus on the sociolinguistic concept rejected what is Chomsky's notion on the one's ability to the spoken language. A language should be adapted to the situational context of the language usages. On the contrary, a language should not be adapted to the ideal style, which focuses on the forms of the language by displaying the actual function of the language. As cited in Huda that the mastery on the grammar as well as the mastery on the social norms are considered as a high level of the language mastery. In this notion, the forms of language and social norms can be interrelated each other to the language usage. The language speakers who are capable to use the language with the appropriate styles based on the contexts of speaking can be taken for granted as the master of communicative competence. So, by having the communicative competence, it helps the language users to transmit, to interpret messages and to give meanings in interactions (Brown, 1987, in Huda).

Second language acquisition is one of the objects of language learning research. In this case, the interactionist approach pertaining to the language acquisition sees that the second or foreign language acquisition as the result of the combined works of the internal factors and the external ones. Then, the development of the communicative competence is the combined result of the learners' effort and his speaking partners in the form of real interactions (Huda, 1999). Furthermore, the process of foreign language/second language acquisition can be processed if the input can be received comprehensibly. The meaning can be comprehensible if the meaning must be adapted to the context, world knowledge, and linguistic competence (Krashen, 1985, in Huda).

Fortunately, the Communicative Language Teaching (CLT), as a demanding language teaching approach to decrease the monotonous and ineffective language learning activities. CLT is currently wide-spreadly used in all non-English speaking countries in which they are considered as English as a Foreign Language (EFL) and English as a Second Language (ESL) countries. It is strongly thought that the communicative ability is as a high professional requirement for getting an excellent communication skill in education. It is also oriented as a 
main goal of a language teaching (Jabeen, 2014). As a result, the use of communicative approach in terms of doing the pedagogical process in favor of getting the goal of language teaching becomes quietly essential. Communication strategy/ approach are taken for granted as the effectively and productively theoretical model in English language teaching since early 1970s. Moreover, it is underlined by the clear concepts by assuming a language is not only as a functional meaning, but as a social meaning as well. Thus it reveals that language learners must understand both linguistic forms and the potential communicative functions and social meanings. That is to say that they attend to relate their linguistic forms to appropriate their own non-linguistic knowledge in favour of interpreting the specific functional meaning intended by the speaker (Littlewood, 1981, in Jabeen, 2014).

As it is said early, a communicative language teaching is based on what Dell Hymes said about communicative competence in a socio-cultural perspective (1996). In addition, it was the extension of what Chomskyan conception revealed on linguistic competence and performance (1965). The socio-cultural point of view suggests the language has to be utilized in the context of language contents. Linguistic and grammatical competence cannot stand by them without the presence of a given cultural social set up to use the language. Furthermore, Hymes added on the normal acquisition belongs to a child that is the acquisition of sentence knowledge is not only grammatical but appropriate as well, because of his / her communicative competence (Hymes, 1972, in Jabeen, 2014). In relation with the practice of the Communicative Language Teaching (CLT), it is much related to the social and interactive activities / classroom participations. There are a number of activities which can be applied, that is pair work, group work, open and cued dialogues, role-play, etc. Thus those classroom activities are called as communicative activities that are designed to feed the opportunity to naturally utilize a target language they have acquired and / or learnt and experienced before in different situations (Jabeen, 2014).

Many kinds of learning methodology which frequently utilized in teaching process could have been various. That others could be modified into more and more, moreover a teacher must have been adapted towards students' circumstance. Furthermore, teaching methods that often applied are Grammar Translation Method, Direct Method, Silent Way, Total Physical Response and Communicative Language Method which have partial aims to achieve national education's purposes within teaching and learning process. Fortunately the writer would like to put forward highlight about the communicative language teaching that concerns on how magnificent student can utter something current orally via interaction of target language as English, and teaching methodology applied to students' nature as the flashback of the highlight which is experienced by student that they considered the subject matter ought not to be sophisticated. Using way of learning should have been set on the social atmosphere which may make students sure about it. Besides presence of teaching technique that will probably interfered as co-operative learning where students is involved in teaching learning process. In accordance with this course Savigon (1983) conveyed that the most effective programs will be those that involve learners in the experience of language as a network of relations among people, things and events. 


\subsection{Needs-Based English Learning}

There are some terms being used to address the concept of need analysis in English as a foreign language / English as second language (EFL/ESL). Need Analysis is called also as needs assessment. In ESL context, the process of designing English curriculum; determining language learning methodologies and carrying out the real course in classroom are parts of needs analysis in terms of language learning activities. A number of scholars and authors have taken into consideration about the role of needs analysis in literature discourses. Moreover, they acknowledged that it is a part of the centrality in language learning design (Songhori, 2008). Needs analysis, the primary step which must be acknowledged, is considered to be the milestone in English for specific purposes (ESP) literatures. It is strongly thought the definition of needs analysis mostly refers to the activities of inspecting, collecting and interpreting the information in form of classroom data that will suggest as the basis of designing and developing an English curriculum which can integrate the students' atmosphere with contextual needs of theirs (Songhori, 2008). According to Brindley (1989) and Berwick (1989) in Songhori (2008), they show that the different types of needs, accounts of various problems being faced in the classroom, and the limitation of using this concept. These must prominently be considered by the curriculum designers.

In addition, Iwai (1999, in Soghori, 2008) stated formal needs analysis is relatively considered as the new one toward language teaching field. However the other way, the informal analysis of needs has been conducted in form of a real teaching-learning objectivity. The contextual practices have been carried out by English teachers in terms of designing curriculum, delivering their courses, and the overall process of assessing the principles of language teaching. Eventually teachers must determine what language point, aims, and targets which students must obtain. Consequently, language teachers will have background belief in terms of designing their curriculum; selecting materials, determining language learning strategies, methods, and even ways of assessments (Songhori, 2008). As foresaid statement, needs analysis in language learning is as the centrality of designing language curriculum, ESP (English for a Specific Purpose). ESP was designed in the 1960s as the text-analysis area. It had increasingly been developed in 1970-1980 in the area of language skills as well as language learning research (Ramirez, 2015). In the context of language learning curriculum development, a teacher must consider about the basic assumption in determining language learning target will be carried out, that is, the analysis of students' needs in language learning programs. Additionally, need-analysis has been considered as a system approach in developing English curriculum (Aprianto, 2016).

Turning to the origins of needs-analysis, where it appears in 1920s in India. It can be traced through several literatures written by Howatt et. Al, (1984, in West, 1994). Furthermore, West had produced one concept coping with the two conflicting and separate concepts of needs, namely what are the requirements that will be conducted by the students to do with the foreign language in the target situation. Next is how language learners might best master the target language during the period of training. Moreover, the concept of ESP has been linked to what Halliday et.al (1964, in West, 1994); English for Special needs. 


\section{References}

Ahmad, Saeed. (2013). Applying Communicative Approach in Teaching English as a Foreign Language; a Case Study of Pakistan. Porta Linguarium, No. 20: 187-203.

Al-Ahdal, et.al,. (2014). A Comparative Study of Proficiency in Speaking and Writing among EFL Learners in Saudi Arabia. American International Journal of Contemporary Research, Vol. 4, N0. 2: 141-149.

Alharbi, Heba, A. (2015). Improving Students' English Speaking Proficiency in Saudi Public Schools. International Journal of Instruction, Vol. 8, No. 1: 105-116

Aprianto, Dedi. (2016). Needs Analysis in English Language Learning (ELL) Curriculum Developments. Journal of English Language Teaching (-Jo-ELT), Vol. 2, No. 3: 64-75.

Boonkit, Kamonpan. (2010). Enhancing the Development of Speaking Skills for a non-Native Speakers of English. Procedia Social and Behavioral Science 2: 1305-1309.

Brooks, Gavin \& Wilson, John. (2014).Using Oral Presentations to Improve Students' English Language Skills. Kwansei Gakuin University Humanities Review, Vol. 19: 199212.

Brown, H. Douglas. (2000). Principles of Language Learning and Teaching(Fourth Edition). New York: Addition Wesley Longman

Darwish, Hosam. (2016). We Couldn't Communicate in English, Could we? ; the Communicative Approach Practices, A Critical View. International Journal of Languages' Education and Teaching, Vol. 4, No. 2: 183-192.

Farooqui, Sabrin. (2007). Developing Speaking Skills of Adult Learners in Private Universities in Bangladesh; Problems and Solutions. Australian Journal of Adult Learning, Vol. 47, No. 1: 95-109.

Hossain, Md. Jamal. (2013). ESP Needs Analysis for Engineering Students; A Learner Centered Approach. Journal of PU, Presidency University, Vol. 2, No. 2: 16-26.

Hopkins, David, B. (2017). An Outline of Nativist and Behaviorist Theories of Language Acquisition; International Conference on Literature, History, Humanities, and Interdisciplinary Studies (LHHISS-17). International College, Siam Technology College, Bangkok, Thailand: 46-48.

Jabeen, Shazi, S. (2014). Implementation of Communicative Approach. Canadian Center of Science and Education, Vol. 7, No. 8, 68-74.

Jones, M. Gail \& Araje, Laura, B. (2002). The Impact of Constructivism of Education; Language, Discourse, and Meaning. American Communication Journal, Vo. 5, No. 3: 110.

Muho, Anita \& Kurani, Aida. (2011). The Role of Interaction in Second Language Acquisition. European Scientific Journal, Vol. 16: 44-54.

Ramirez, C.Gonzalez.(2015). English for Specific Purposes; Brief History and Definitions. Revista De Linguas Moderna. Vol. 23, 379-386.

Sarem, Saeid. N. \& Shirzadi, Yusef. (2014). A Critical Review of the Interactionist Approach to Second Language Acquisition. Journal of Applied Linguistics and Language Research, Vol. 1, No. 1: 62-74.

Scarcella, et.al (1990). Developing Communicative Competence in a Second Language; Series on Issues in Second Language Research. Boston; Heinle and Heinle Publishers.

Savignon, Sandra, J. (2007). Communicative Language Teaching; State of the Art. TESOL Quartenterly, Vol. 25, No. 2: 261-277. 
Songhori, Mehdi, H. (2008). Introduction to Needs Analysis; English for Specific Purposes World. Azad University of Baft, Kerman, No. 4: 1-25.

Tomic, Welco. (1993). Behaviorism and Cognitivism in Education. A Journal of Human Behavior, Vol. 30, No.3/4: 38-46.

Principles of Language learning and the Role of Teacher (On December $12^{\text {th }}, 2018$ ). http://www.tesol.org.TESOL International Association: 3-10 (2017).

West, Richard.(2008). Needs Analysis in Language Teaching. http://journals.cambridge.org/LTA, Vol. 27, No. 1: 1-19. 